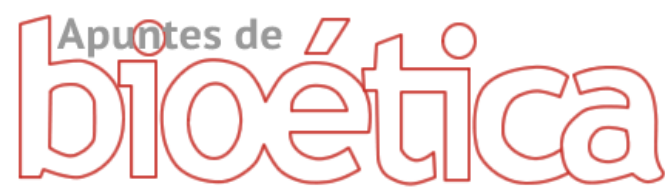

https://doi.org/10.35383/apuntes.v2i2.288

\title{
Estatuto jurídico del embrión humano
}

\author{
Rosa De Jesús Sánchez Barragán ${ }^{1}$
}

\section{INFORMACIÓN DEL ARTÍCULO RESUMEN}

\section{Historia del artículo:}

Recibido el 24 de setiembre de 2019

Aceptado el 30 de diciembre de 2019

\section{Palabras claves: \\ Embrión humano \\ Sujeto de derecho \\ Derecho a la vida \\ Estatuto jurídico \\ Persona \\ Dignidad humana \\ capacidad \\ protección}

El presente artículo pretende aportar unas breves ideas sobre el estatuto jurídico del embrión humano. Además de llevar a cabo una aproximación al fundamento en el que se basa la afirmación de que el embrión, por el hecho de ser persona, merece una protección jurídica $y$, por tanto, debe ser considerado un auténtico sujeto de derecho. De tal forma que la ley positiva no posea legitimidad para privarle de su personalidad, ni limitar sus derechos naturales. La única capacidad de limitación que posee la ley positiva se encuentra en la capacidad de obrar que tiene toda persona.

\section{Legal status of the human embryo}

Keywords:
Human embryo
Subject of law
Right to life
Legal status
Person
Human dignity
capacity
protection

\section{Keywords:}

Human embryo

Right to life

Legal status

Human dignity

protection

\section{ABSTRACT}

This article aims to provide some brief ideas about the legal status of the human embryo. In addition to carrying out an approach to the foundation on which the claim is based that the embryo, due to the fact of being a person, deserves legal protection and, therefore, should be considered a true subject of law. So that the positive law does not have legitimacy to deprive him of his personality, or limit his natural rights. The only capacity for limitation that the positive law has is found in the capacity to act that every person has. Here place summary in English

\footnotetext{
${ }^{1}$ Doctora Internacional en Derecho por la Universidad de Navarra (España), Magíster en Derecho Civil y Comercial por la Universidad Nacional Pedro Ruiz Gallo, Magíster en Bioética y Formación por el Pontificio Instituto Juan Pablo II de la Universidad Lateranense (Roma). Magíster en Derechos Fundamentales por la Universidad Autónoma de Madrid (España). Con estudios de postgrado en Bases antropológicas y éticas de la investigación en la Universidad por la Universidad de Navarra. Postgrado en Investigación científica por la Universidad Católica Santo Toribio de Mogrovejo. Abogada por la Universidad Nacional Pedro Ruiz Gallo. Directora del Instituto de Bioética, Miembro del Instituto de Ciencias para el Matrimonio y la Familia - USAT. Coordinadora General de la Maestría en Persona, Matrimonio y Familia de la Universidad Católica Santo Toribio de Mogrovejo. Docente e investigadora de la Facultad de Derecho - USAT. Miembro del Grupo de Investigación WINN de la Universidad de Navarra. Email: rosadejesuss@yahoo.es Orcid: https://orcid.org/0000-0002-7726-9775
} 


\section{Introducción}

Hasta el siglo XX el ser humano no tenía la capacidad de intervenir sobre los embriones humanos y, por tanto, carecía de sentido preguntarse cómo debían ser tratados. La única posibilidad la planteaba el aborto, práctica que en general no estaba permitida. Posteriormente, en la segunda mitad del siglo $\mathrm{XX}$, con la aparición de las nuevas tecnologías biomédicas ( $y$, en especial, de los fármacos que actúan eliminando los embriones humanos, así como la posibilidad de crear embriones humanos en el laboratorio) ${ }^{2}$, el ser humano empezó a adquirir capacidad de actuación, interviniendo sobre la vida de los embriones, tanto fuera como dentro del útero de la mujer. Esto generó amplios debates sobre lo que el Derecho debía permitir y prohibir. Se trataba de establecer, en definitiva, el estatuto jurídico del embrión humano.

A continuación trataremos de dar algunos argumentos de porque el embrión humano debe ser considerado un sujeto de derecho y por ende debe gozar de una total protección jurídica.

\section{Fundamento ontológico del derecho a la vida del embrión humano}

Por fundamento del derecho entendemos "aquello en virtud del cual el titular esta posibilitado para poseer el título"3. Por su parte, J. HERVADA considera que el título, es "aquello en virtud del cual la cosa es atribuida a su titular"4. En este sentido, el fundamento del derecho es la

\footnotetext{
2 En este sentido, V. Bellver afirma que "Ese estado de cosas cambió radicalmente hacia los años cincuenta del siglo pasado. Algunos médicos, entre los que destaca ROBERT EDWARDS -el "padre" de Louise Brown, la primera niña nacida por fecundación in vitro en 1978-, decidieron llevar a cabo con gametos y embriones humanos los experimentos que hasta entonces venían haciendo con ratones. Se abría una puerta que, por un lado, planteaba problemas filosóficos y éticos de la más alta envergadura, pero, por otro, descubría extraordinarias posibilidades de conocimiento, intervención y manipulación en el proceso de la reproducción humana" (Bellver, V., "Estatuto jurídico del embrión humano", en La humanidad in vitro, Ballesteros, J. (coord.), Aparisi Miralles, A., et al., op. cit., p. 243.

${ }^{3}$ Hervada, J., Lecciones propedéuticas de filosofía del derecho, op. cit., p. 232. En este sentido J. Hervada considera que el título, es "aquello en virtud del cual la cosa es atribuida a su titular" (Ibidem).

${ }^{4}$ Ibidem.
}

naturaleza humana o la condición de persona ${ }^{5}$, siendo el punto de referencia del derecho la dignidad de todo ser humano ${ }^{6}$. De acuerdo con ello, el presupuesto del derecho, el ser humano y su dignidad, es una realidad dada al derecho, no creada por él.

En realidad, uno de los avances jurídicos más importantes es la convicción sobre esta radical dignidad de toda vida humana ${ }^{7}$. Así, en la universalidad del respeto incondicionado al otro, el derecho encuentra su fundamento. En este sentido A. L., MARTínEZ-PUJALTE, sostiene que "La experiencia nos muestra que el hombre se halla abierto esencialmente al otro, a los demás, necesita al otro: se halla inmerso en una relación social de la que no le es posible prescindir. La socialidad o exigencia ontológica del otro aparece, pues, como un rasgo constitutivo esencial del ser hombre, del que deriva, precisamente, la razón de ser del Derecho: el Derecho existe, en pocas palabras, porque el hombre es un ser social" ${ }^{8}$. Por ello se puede afirmar que el Derecho surge como un medio al servicio de la adecuada convivencia entre los seres humanos, en especial de los más débiles, y para custodiar los derechos de la personas ${ }^{9}$.

Ya se ha hecho referencia anteriormente a que estos presupuestos no son unánimemente aceptados en la actualidad, al existir una fuerte corriente de pensamiento que hace depender la dignidad y el valor de la vida humana de su grado de desarrollo, o de ciertas cualidades, como pueden ser la autonomía o la calidad de vida $^{10}$.

\footnotetext{
${ }^{5}$ Cfr. Ibidem., p. 233

${ }^{6}$ Aparisi M. A., "La dignidad humana como fundamento del orden jurídico positivo" Conferencia inaugural de la Facultad de derecho de la Universidad de Istmo - Guatemala, 2001, p. 22 http://www.unis.edu.gt/ap/fetch/dignidad-humana-fundamento-ordenjuridico.pdf (visitado: 11 de julio 2016).

${ }^{7}$ Cfr. Ibidem.

${ }^{8}$ Martínez-Pujalte, A. L., "Los derechos humanos como derechos inalienables" en Derechos humanos, Ballesteros, J. (ed.), Tecnos, Madrid, 1992, pp. 92-93.

${ }^{9}$ Cfr. Díaz de Terán Velasco, M.C., Derecho y nueva eugenesia: un estudio desde la ley 35/88, de 22 de noviembre de técnicas de reproducción asistida op. cit., p. 261

${ }^{10} \mathrm{Cfr}$. Aparisi M. A., "El principio de la dignidad humana como fundamento de un bioderecho global", op. cit., p. 218.
} 
Dichas concepciones reduccionistas $y$ excluyentes de la dignidad humana del embrión, deben ser contrastadas con la concepción ontológica, que considera al embrión humano valioso por lo que es, no por las cualidades o capacidades que posee ${ }^{11}$. Esta visión entiende que todo embrión merece respeto incondicionado. Es más, el derecho a la vida sería el principal derecho a custodiar, incluso jerárquicamente superior al resto, ya que si se carece de él no pueden protegerse los demás, así como tampoco a la persona ${ }^{12}$.

De lo dicho puede afirmarse que el derecho a la vida deriva de la dignidad humana y ésta encuentra su fundamento en la naturaleza humana. Esta necesidad de proteger la vida surge de la primera inclinación o tendencia humana, que se encuentra dirigida a conservar el ser y a evitar todo aquello que la obstaculiza. Por ello, el primer principio de la razón práctica o ley natural "ordena conservar la vida y evitar lo que la obstaculice" ${ }^{13}$. De ahí que sean reprobables todas aquellas acciones que atenten contra la vida, porque implicarán una agresión contra la misma dignidad de la persona $y$, por ende, contra su naturaleza humana ${ }^{14}$. El desafío actual radica en descubrir que toda vida humana, independientemente del estadio que se encuentre, es una persona (sea feto, embrión, niño, adulto o anciano) y, por lo tanto, tiene el mismo valor y la misma dignidad. Asi M. DíAZ DE TERÁN puede afirmar que "la misión del Derecho es, por tanto la tutela integral de la persona"15, lo cual aporta aún mayores razones para

\footnotetext{
${ }^{11}$ Ibidem.

${ }^{12} \mathrm{Cfr}$. Ibidem

${ }^{13}$ Cfr. Hervada, J., Introducción crítica al Derecho Natural, op. cit., p. 197.

14 "La vida humana es un bien absoluto no solo para el hombre en su calidad de persona sino también para el concebido por ser sujeto de derecho y que goza de dicha calidad, pero un bien absoluto ha de ser protegido siempre y bajo cualquier circunstancia, y no debería ser dejado al olvido solo por resultados o peticiones sociales o peor aún en beneficio de la ciencia, del reconocimiento público y del mal del siglo XX: la codicia; pues los actos humanos deben estar ordenados siempre hacer el bien y evitar el mal, esa característica es la que los hace humanos". (Sanchez Barragán, R., "Protección de la Vida Prenatal, con especial relevancia en el Derecho Constitucional Español", en Revista de la Universidad Católica Santo Toribio de Mogrovejo, 2008, pp. 38-39).

${ }^{15}$ Díaz de Terán Velasco, M.C., Derecho y nueva eugenesia: un estudio desde la ley 35/88, de 22 de noviembre de técnicas de reproducción asistida, op. cit., p. 260.
}

proteger a esa persona frágil e indefensa que es el embrión humano ${ }^{16}$.

En definitiva, el fundamento ontológico del derecho radica en el respeto a la persona y a su dignidad. De ello se deriva la necesaria protección del derecho a la vida en todas sus etapas de desarrollo.

Teniendo en cuenta lo señalado, J. Hervada considera que "la norma jurídica positiva no puede abrogar los mandatos y prohibiciones naturales; es decir, no puede destruir la obligatoriedad de la norma jurídica natural que prescribe 0 prohíbe una conducta" ${ }^{17}$. En consecuencia, la ley positiva que vulnere algún precepto natural o se oponga a la ley natural, siempre será una norma injusta o arbitraria y una norma de esta naturaleza impone solo coacción o restricción, más no racionalidad; más que una ley sería una apariencia de ley, por ser en esencia injusta y no ser acorde con el derecho natural, que exige, en principio, el respeto a la dignidad de la persona humana. En este sentido, puede decirse que, si un acto es justo por derecho natural no debe ser ilegal desde el punto de vista del derecho positivo, o lo contrario; si un acto es injusto desde el derecho natural no puede ser considerado como legítimo por el derecho positivo, pues con ello se rompería la unidad del sistema jurídico o se atentaría en todo caso, contra la coherencia que debe existir en un ordenamiento jurídico. Por ello, el legislador no autoriza comportamientos que atenten contra la dignidad del ser humano, ya que ello vulneraría las exigencias de la ley natural.

\section{Protección jurídica del embrión humano}

Ante la realidad de la vida humana embrionaria, existen, al menos, dos posturas

\footnotetext{
${ }^{16}$ Como señala J. Ballesteros, la capacidad de reconocimiento del otro exige un acto de acogida a su alteridad. Precisamente, la atención al "rostro del otro" debe tener en cuenta su especial vulnerabilidad en los momentos en que se revela más frágil, cfr. Ballesteros, J., "Individualismo y universalidad de los derechos", en Persona y Derecho, 41 (1999), p. 18 y ss.

${ }^{17}$ Cfr. Hervada, J., Introducción crítica al Derecho Natural, op. cit., p. 197.
} 
relativas a su protección jurídica: a) la defendida por aquellos que consideran que la vida debe protegerse gradualmente; y b) la representada por quienes consideran que la vida humana debe estar garantizada jurídicamente desde el mismo instante de su existencia. A continuación se hará una breve referencia a cada una de estas posiciones.

\section{A. Gradualidad y potencialidad}

Para los propulsores de esta postura, la protección de la vida se realiza de forma "gradual", por lo que el derecho debe garantizar la vida en la medida en que ésta progresa y se intensifica, teniendo como referencia ciertos cambios cuantitativos en su desarrollo, en especial, el del nacimiento.

En España esta perspectiva gradual fue acogida, entre otras, por la STCE $53 / 85^{18}$, referente al sistema de indicaciones en la llamada interrupción voluntaria del embarazo. Posteriormente también fue adoptada por la Ley 42/1988 del 28 de diciembre de $1988^{19}$, sobre Donación y Utilización de embriones y fetos humanos o de células, tejidos u órganos, y por la Ley $35 / 1988^{20}$ del 22 de noviembre sobre Técnicas de Reproducción Asistida. A nivel jurisprudencial fue nuevamente confirmada por la STCE 212/1996 del 19 de diciembre de 199621, relativa a las técnicas de reproducción asistida, y por la STCE 116/1999 del 17 de junio de 199922. En esta última Sentencia, se recalcó que el momento decisivo para el reconocimiento de un

\footnotetext{
${ }^{18}$ STCE 53/1985, op. cit., Fundamento Jurídico número 14. p. 21.

${ }^{19}$ Ley de donación y utilización de embriones y fetos humanos o de sus células, tejidos u órganos (Ley 42/1988, de 28 de diciembre) en BOE Núm. 314, de 31 de diciembre de 1988, pp. 6766 a 36767.

https://www.boe.es/boe/dias/1988/12/31/pdfs/A36766-36767.pdf (visitado: 12 de julio 2016)

${ }^{20}$ Ley sobre Técnicas de Reproducción Asistida (Ley 35/1988, de 22 de noviembre) en BOE Núm. 282, de 24 de noviembre de 1988, pp. 33373 a 33378.

https://www.boe.es/boe/dias/1988/11/24/pdfs/A33373-33378.pdf (visitado:

12 de julio 2016)

${ }^{21}$ STCE 212/1996, op. cit., pp. $32-43$.

${ }^{22}$ STCE 116/1999, op.cit., pp. 67-80.
}

estatus jurídico al embrión humano es el de su anidación o implantación en el útero materno ${ }^{23}$.

\section{B. La continuidad lógica}

Esta segunda posición se fundamenta en el hecho de la continuidad biológica de la vida del ser humano, la cual se inicia con la fecundación concluye con la muerte natural.

Dicha posición quedó reflejada en España en el voto Particular discrepante en la STCE 212/1996, emitido por el Magistrado del TCE J. GABALDÓN LÓPEZ. En él sostuvo que era necesario extender a los seres humanos, desde el comienzo de su existencia biológica, las mismas garantías y protección de que goza la vida de los ya nacidos, estableciendo la imposibilidad de trazar cualesquiera distinción entre sus fases de desarrollo que no resulten, a la postre, puramente arbitrarias. Para este autor, la investigación genética ha demostrado que "desde la unión de los gametos masculino y femenino existe un ser distinto perteneciente a la especie homos sapiens a quien no le falta ya nada para poder ser definido como hombre (...) y al que (...) le caben ya, según el art. 10.1 de la Constitución, la dignidad de la persona y la aplicación de su principio al libre desarrollo incluso antes y aún al margen de la adquisición formal de la personalidad jurídica según la ley positiva"24.

En la medida en que "el embrión humano dispone de un genoma completamente individual desde la fecundación" y "se desarrolla continuamente desde ese momento, sin saltos en su desarrollo", habría que admitir que el "embrión no es una persona potencial sino actualmente una persona humana con potencialidades todavía no actualizadas". En consecuencia, a su juicio, "los conceptos de

\footnotetext{
23 Cfr. Peñaranda, E., Los Nuevos Desafíos de Reproducción Asistida, Reflexiones Éticas y jurídicas desde la perspectiva del Derecho Penal, Editorial Fundación Medicina y Humanidades médicas, Madrid, 2006, p. 15.

${ }^{24}$ Gabaldón, J., "Libre desarrollo de la Personalidad y derecho a la vida", en Persona y Derecho, Editorial Aranzadi Civitas, Madrid, 2001, p. 134
} 
hombre y de persona son inseparables" y cualquier "intento de separación responde a una mera razón estratatégica" ${ }^{25}$.

Esta postura también es seguida por el constitucionalista alemán E. WolfGANG BÖCKENFÖRD, quien critica como arbitrarios todos los intentos -cada vez más extendidos en la literatura filosófica y jurídica alemana-, de diferenciar entre vida humana y vida personal. Sostiene este autor que el objetivo de estas posiciones es configurar una noción de persona entendida como un concepto más reducido que el de ser humano. Para evitarlo, E. WolfGANG BÖCKENFÖRD incide en la necesidad de que "el embrión humano sea tratado también en su fase vital más temprana como titular de la dignidad humana y del derecho a la vida que reconoce la Constitución alemana"26.

\section{El embrión ante el derecho}

El mayor obstáculo para el reconocimiento jurídico de la dignidad humana al embrión radica en la negativa a atribuirle el estatuto de persona, con la consiguiente imposibilidad de ser considerado un titular de derecho $\mathrm{y}$, por tanto, un sujeto de derecho ${ }^{27}$.

Como es sabido, en el mundo del derecho a las personas se les da la categoría de sujetos de derecho, mientras que las cosas son objetos de derecho. Esta realidad, sin embargo, varía según las legislaciones de los distintos Estados. Así, para el sistema jurídico peruano el embrión es un sujeto de derecho ${ }^{28}$, para otros ordenamientos,

\footnotetext{
25 Ibidem., p. 155; PeÑaRanda, E., Los Nuevos Desafíos de Reproducción Asistida, Reflexiones Éticas y jurídicas desde la perspectiva del Derecho Penal, op. cit., p. 14

${ }^{26} \mathrm{Cfr}$. BÖCKENFÖRD DE E-W, Menschenwürde als normatives Prinzip. Die Grunderechte in der bioethischen Debatte. JZ. 2003, pp. 810-813.

${ }^{27}$ Cfr. Ollero Tassara, A., "Todos tiene derecho a la vida ¿hacia un concepto constitucional de persona?", en Bioderecho entre la vida y la muerte, Thomson-Aranzadi, Cizur Menor (Navarra), 2006, pp. 100

${ }^{28}$ La Constitución Política del Perú (CPP) en su artículo 2 establece que: "(...) El concebido es sujeto de derecho en todo cuanto le favorece" y en el artículo 1 del Código Civil (CC) peruano señala "La vida humana comienza con la concepción. El concebido es sujeto de derecho para todo cuanto le favorece. La atribución de derechos patrimoniales está condicionada a que nazca vivo".
}

como puede ser el español, se está ante una realidad mixta -según la cual embrión es un bien jurídico constitucionalmente protegido-, mientras que, finalmente, para otros sistemas jurídicos se está ante un puro objeto ${ }^{29}$.

Partiendo de esta realidad, en el presente epígrafe se aportarán algunas ideas relativas a si desde el plano jurídico resulta adecuado diferenciar entre ser humano y persona, considerando sujeto de derecho exclusivamente a quienes se les ha concedido personalidad jurídica o, por el contrario, la cualidad de persona debe está ligada al concepto de sujeto de derecho. Además, se analizará si la desprotección legal de la vida humana que se encuentra en fases iniciales, o no posee determinadas cualidades, es conforme al sentido último del derecho.

\section{A. Concepto jurídico de persona}

La persona, al ser dueña de sus propios actos, posee, consecuentemente, un dominio moral $y$, por tanto, también un dominio jurídico $^{30}$. En este sentido J. HERVADA afirma que: “(...) el ser y los actos de la persona, por pertenecerle, son derecho suyo frente a los demás"31. De esta afirmación, siguiendo a $\mathrm{M}$. DíAZ DE TERÁn, se deduce que el ser sujeto de derecho -o ser persona en sentido jurídico- tiene un origen natural ${ }^{32}$. Por ello, esta juridicidad natural implica que, por naturaleza, el ser humano se encuentra vinculado jurídicamente con los otros, siendo, por tanto, protagonista del sistema jurídico. De ahí se concluye que ser persona no es un dato cuyo origen sea positivo, sino natural, porque los individuos humanos son,

\footnotetext{
${ }^{29}$ STCE 53/1985, op.cit., Fundamento Jurídico número 7. p. 19.

${ }^{30}$ Cfr. Díaz de Terán Velasco, M.C., Derecho y nueva eugenesia: un estudio desde la ley 35/88, de 22 de noviembre de técnicas de reproducción asistida, op. cit., pp. $251-252$.

${ }^{31}$ Hervada, J., "Concepto jurídico y concepto filosófico de persona", en La Ley, 1, (1981), p. 942.

${ }^{32}$ Cfr. Díaz de Terán Velasco, M.C., Derecho y nueva eugenesia: un estudio desde la ley 35/88, de 22 de noviembre de técnicas de reproducción asistida op. cit., p. 252
} 
ya estructuralmente, sujetos de derecho ${ }^{33}$, personas en sentido jurídico. La persona humana posee en sí misma una dimensión jurídica. Por ello, el concepto jurídico de persona debe seguir necesariamente al concepto ontológico de persona; solo es admisible una distinción lógica, en razón de la forma o de la perspectiva ${ }^{34}$. En esta línea, J. HERVADA considera que:

"La condición ontológica de persona incluye la subjetividad jurídica, de modo que el concepto jurídico de persona no puede ser otra cosa que el concepto mismo de persona en sentido ontológico, reducido a los términos de la ciencia jurídica. Dicho en otros términos, el concepto jurídico de persona no es más que aquel concepto que manifiesta lo jurídico de la persona o ser humano"35.

De ello puede deducirse que, siendo la persona una realidad única e irrepetible, resulta imposible separar el concepto jurídico de persona del concepto ontológico. En este sentido, el derecho no incorpora nada a la estructura ontológica de la persona, sino que reconoce y protege su titularidad natural y la dignidad que le corresponde por el hecho de ser persona ${ }^{36}$. Por tanto, como afirma M. DíAZ DE TERÁN, siguiendo el pensamiento de J. HERVADA, el concepto ontológico y el concepto jurídico de persona se encuentran solapados o, más bien, el concepto jurídico se encuentra contenido en el ontológico ${ }^{37}$.

\footnotetext{
${ }^{33}$ Cfr. Hervada, J., "Concepto jurídico y concepto filosófico de persona", op. cit., p. 943. En el mismo sentido Martínez De Aguirre y Aldaz, C., "¿El nacimiento determina la personalidad? (Reflexiones sobre el concepto jurídico de persona, con un epílogo sobre la situación jurídica del concebido)", en Actualidad Civil, 31 (2001), p. 1103.

${ }^{34}$ Cfr. Hoyos Castañeda, L. M., El concepto jurídico de persona, EUNSA, Pamplona, 1989, p. 44.

${ }^{35}$ Hervada, J., "Concepto jurídico y concepto filosófico de persona", op. cit., p. 945.

${ }^{36} \mathrm{Cfr}$. Hoyos Castañeda, L. M., El concepto jurídico de persona, op. cit., p. 533.

${ }^{37}$ Cfr. Díaz de Terán Velasco, M.C., Derecho y nueva eugenesia: un estudio desde la ley 35/88, de 22 de noviembre de técnicas de reproducción asistida, op. cit., p. 253. Cfr. Hervada, J., Introducción crítica al Derecho Natural, op. cit., p. 143.
}

No obstante, es evidente que esta visión no es, ni mucho menos, unánimemente aceptada. De todos es sabido que el positivismo jurídico sostiene que la personalidad jurídica es concedida por el derecho positivo, y no es una realidad dada, o poseída, inherentemente por el ser humano ${ }^{38}$. De acuerdo con ello, solo serán personas aquellos sujetos a quienes el derecho positivo les conceda la personalidad ${ }^{39}$. De ello resulta que la persona existirá en la medida en que el ordenamiento jurídico le conceda tal prerrogativa. $Y$ en este marco, por ejemplo, no se plantea problema legal alguno ante disposiciones que desprotegen totalmente la vida humana en sus estados más incipientes. En el fondo, como es evidente, subyace una distinción entre el concepto ontológico y el concepto jurídico de persona ${ }^{40}$.

Siguiendo a J. HervadA, se considera que "el positivismo jurídico lleva el tema del derecho a un callejón sin salida. No solo destruye cualquier dimensión natural de justicia, que queda reducida a mera legalidad (...), sino que además despoja a la persona humana de toda juridicidad inherente a ella, lo cual es rigurosamente imposible" ${ }^{\prime 41}$, desembocando, en definitiva, en lo ya señalado: no toda persona en sentido ontológico será persona en sentido jurídico ${ }^{42}$.

Como se ha indicado en líneas anteriores, estructuralmente la persona es dueña de su propio ser. Por ello, un pilar esencial de todo derecho es la idea de que todo ser humano es persona, de que allí donde haya un ser humano, hay una persona en sentido jurídico. $Y$ ello implica la capacidad de apropiarse y de ser

\footnotetext{
${ }^{38}$ Cfr. Ibidem., p. 141

${ }^{39}$ Cfr. Hervada, J., "Concepto jurídico y concepto filosófico de persona op. cit., p. 945

${ }^{40}$ Cfr. Díaz de Terán Velasco, M.C., Derecho y nueva eugenesia: un estudio desde la ley 35/88, de 22 de noviembre de técnicas de reproducción asistida. op. cit., p. 253

${ }^{41}$ Hervada, J., Introducción crítica al Derecho Natural, op. cit., p. 142.

${ }^{42}$ Cfr. Hervada, J., "Concepto jurídico y concepto filosófico de persona", op. cit., p. 944
} 
titular de los derechos y deberes naturales ${ }^{43}$. De ahí se infiere que negar la personalidad jurídica a un ser humano, cualquiera que sea su condición o estado, es una injusticia ${ }^{44}$.

En conclusión, la idea de que todo ser humano es una persona es una conquista, no solo del derecho civil, sino del derecho en general $^{45}$. Este presupuesto se encuentra fundamentado en la propia estructura humana, de tal modo que para tener la condición de persona (tanto desde el plano ontológico como jurídico), solo se requiere un criterio: la pertenencia biológica a la especie humana ${ }^{46}$.

\section{b) Personalidad y capacidad}

Un tema importante, al abordar la cuestión de la condición de sujeto de derecho del embrión, son los conceptos de personalidad y capacidad. En realidad, una adecuada comprensión de los mismos permitirá sentar correctamente las bases para proteger mejor a todo sujeto de derecho $y$, de forma especial, a los más frágiles y vulnerables, como son los embriones y los enfermos.

La doctrina civilista, en ocasiones, ha confundido los conceptos de personalidad y de capacidad jurídica. Como sostiene D. BARBERO, es suficiente con "pensar que la "personalidad" es un quid simple, mientras que la capacidad es un quantum y, por tanto, susceptible de medición por grados. Se puede ser, como persona, más o

\footnotetext{
${ }^{43}$ Cfr. Hervada, J., Introducción crítica al Derecho Natural, op. cit, p. 143. Además, el mismo autor sostiene que "la condición ontológica de persona incluye la subjetividad jurídica, de modo que el concepto jurídico de persona no puede ser otra cosa que el mismo concepto de persona en sentido ontológico, reducido a los términos de la ciencia jurídica" (Ibidem).

${ }^{44} \mathrm{Cfr}$. Hervada, J., "Concepto jurídico y concepto filosófico de persona op. cit., p. 944

45 Cfr. Doral García, J. A., “Concepto filosófico y concepto jurídico de persona", en Persona y Derecho, 2 (1975), p. 115; Montes Penades, V. L, "El significado institucional de la idea de persona", en LóPEZ, A. Y MONTES V. L. (coord.), Derecho civil. Parte general, Tirant lo Blanch, Valencia, 1995, p. 239.

${ }^{46}$ Spaemann, R., Personas. Acerca de la distinción entre "algo" y "alguien", op. cit., p. 236. Como se puso de manifiesto en el segundo capítulo, "(...) aquello que es relevante para el reconocimiento del ser de la persona es su pertenencia, por naturaleza, a la especie humana" (Palazzani, L., "El concepto de persona en el debate bioético y biojurídico actual", en Medicina y Ética, 1, (1997), p. 29).
}

menos capaz, no se puede ser más o menos persona. Persona se es $o$ no se es radicalmente" ${ }^{\prime 7}$. De lo dicho, puede deducirse que el concepto de persona es distinto y previo al de capacidad. El ordenamiento jurídico no tiene legitimidad para conceder la personalidad, sino que reconoce la existencia previa de la persona $y$, en consecuencia, de los derechos naturales innatos a ella ${ }^{48}$. En este sentido L. M. DíEZ-PICAZO y A. GULLón BALlesteros, sostienen que "la personalidad no es mera cualidad que el ordenamiento jurídico pueda atribuir de manera arbitraria, es una exigencia de la naturaleza y dignidad del hombre que el Derecho no tiene más remedio que reconocer"49. Además, los mismos autores consideran que:

\section{“(...) no basta con reconocerle} la aptitud para ser sujeto de derechos y de obligaciones o, si se quiere, de relaciones jurídicas, pues sería minimizarla (a la persona). Significa, sobre todo, que las normas jurídicas han de darse y desarrollarse teniendo en cuenta la dignidad del hombre como persona y sus atributos" ${ }^{\prime 50}$.

Como puede apreciarse, la personalidad jurídica es una dimensión de la persona, es decir, del sujeto DE derecho, que se distingue totalmente de los derechos y deberes que goza la persona en su condición de tal. Por tanto, gozará de derechos y deberes naturales y de derechos y deberes positivos. No obstante, el ordenamiento jurídico sí puede cuantificar la capacidad $^{51}$. La ley positiva podrá regular la capacidad en función del orden público y la seguridad jurídica, pero esta potestad de regulación debe sujetarse a dos límites: a) la ley positiva no puede negar de raíz la personalidad a

\footnotetext{
${ }^{47}$ Barbero, D., Sistema del derecho privado, vol. I, Editorial Jurídicas Europa América, Buenos Aires, 1967, p. 191.

${ }^{48}$ García Amigo, M., Instituciones de Derecho civil, (vol. I), Editorial Revista de Derecho Privado, 1979, p. 295.

${ }^{49}$ Díez-Picazo, L. M. y Gullón Ballesteros, A., Sistema de Derecho Civil, op. cit., p. 223.

50 Ibidem.

51 Cfr. Hoyos Castañeda, L. M., El concepto jurídico de persona, EUNSA Pamplona, 1989, p. 169
} 
un ser humano, cualquiera que sea su condición; y b) la limitación de la personalidad no puede extenderse a los derechos naturales ${ }^{52}$. De este modo, la calidad de persona del embrión humano no puede ser negada, como tampoco se le puede limitar sus derechos naturales, como por ejemplo el derecho a la vida, a la integridad física, entre otros ${ }^{53}$.

Un ejemplo de limitación de la capacidad puede encontrase en el artículo 29 del CC español en dónde se hace referencia al concebido $^{54}$. En este sentido C. MARTínEZ DE AGUIRRE Y ALDAZ, señala que: “(...) lo que el artículo 29 CC añade a esa limitada personalidad que tiene el concebido por el mero hecho de tratarse de un ser humano, es la potencialidad de ser sujeto activo y pasivo de cualesquiera otras relaciones jurídicas. Es decir, la capacidad jurídica $(\ldots)^{\prime \prime 55}$.

En conclusión, se puede afirmar que "el ordenamiento jurídico puede limitar el contenido de la personalidad cuando está ante un ser humano, pero no puede negarle la raíz de la misma. Y no puede porque, en realidad no se la ha concedido, sino que el ser humano la posee como inherente a su propia naturaleza" ${ }^{56}$.

\footnotetext{
${ }^{52}$ Cfr. Hervada, J., "Concepto jurídico y concepto filosófico de persona $o p$. cit., p. 946. En el mismo sentido, DORAL GARCíA, J. A., "Concepto filosófico y concepto jurídico de persona", op. cit., p. 130.

${ }^{53}$ Respecto de los derechos naturales se puede consultar Hervada, J., Introducción crítica al Derecho Natural, op. cit., pp. 111-114. Además M. Aguirre Y Aldaz señalan: "todo ser humano (..) es sujeto titular de esos derechos naturales primarios (a la vida, a la integridad física) (...). Desde este punto de vista, ese ser humano, en cuanto es sujeto de derechos, tiene personalidad jurídica. (...) Sin embargo, sucede que antes del nacimiento, su personalidad está limitada a la titularidad actual de esos derechos naturales primarios (...). El ordenamiento jurídico español, a través del artículo 29 C.C, impide al ser humano no nacido tomar parte autónomamente, y con plenitud en la vida jurídica. Tal limitación podría encontrar un fundamento razonable en cuanto que tampoco toma parte autónomamente en la vida social. Antes del nacimiento su personalidad está, pues, restringida".

${ }^{54}$ Artículo 29 del CC español: El nacimiento determina la personalidad; pero el concebido se tiene por nacido para todos los efectos que le sean favorables, siempre que nazca con las condiciones que expresa el artículo siguiente (Real Decreto de 24 de julio de 1889 por el que se publica el Código Civil en BOE núm. 206, de 25/07/1889.

https://www.boe.es/buscar/act.php?id=BOE-A-1889

$763 \& \mathrm{tn}=1 \& p=20151006 \& v d=$ \#art29 (visitado: 18 de julio 2016)

55 Martínez De Aguirre Y Aldaz, C., “¿El nacimiento determina la personalidad? (Reflexiones sobre el concepto jurídico de persona, con un epílogo sobre la situación jurídica del concebido)", en Actualidad Civil, 31 (2001), p. 1106

${ }^{56}$ Ibidem., p. 1104.
}

Además, el Derecho no crea una realidad nueva, sino que parte de una realidad concreta, ya dada, que es la persona. Por ello, la función del derecho debe limitarse a reconocer la cualidad de persona a todo ser humano, sin discriminar a ninguno ${ }^{57}$. J. A. DORAL afirma que "de no reconocerse la personalidad del hombre en su íntegra realidad desaparecería toda posibilidad de determinar el fundamento del Derecho y de la Justicia"58. Por lo tanto, se concluye que todo ser humano, independientemente de la fase del desarrollo en que se encuentre, es persona y, más aún, cualquiera que sea la forma a través de la haya sido concebido, ya sea natural o artificial, es una persona. En consecuencia, el derecho tiene la obligación de otorgarle la protección jurídica que se merece una persona ${ }^{59}$.

\section{c) El embrión como sujeto de derecho}

Platear el tema del sujeto de derecho es referirse a la persona desde la perspectiva jurídica, es decir al sujeto protagonista del orden social y jurídico. Podría ser definido como el sujeto capaz de derechos obligaciones, o como el sujeto titular de derechos y deberes, tratándose, en definitiva, de un ser ante el derecho ${ }^{60}$. Frente a ello, y en una posición antagónica, se situaría la consideración de la persona como un objeto de derecho ${ }^{61}$.

Llegados a este punto, conviene hacer una matización: el concepto filosófico y el jurídico de persona, aunque se aplican a un mismo sujeto, no son sinónimos. Como refiere J. Hervada, "una cosa es la distinción de conceptos y otra la

\footnotetext{
${ }^{57}$ Díaz de Terán Velasco, M.C., Derecho y nueva eugenesia: un estudio desde la ley 35/88, de 22 de noviembre de técnicas de reproducción asistida, op. cit., p. 258

${ }^{58}$ Doral García, J. A., "Concepto filosófico y concepto jurídico de persona", op. cit., p. 123

${ }^{59}$ Díaz de Terán Velasco, M.C., Derecho y nueva eugenesia: un estudio desde la ley 35/88, de 22 de noviembre de técnicas de reproducción asistida, op. cit., p. 259.

${ }^{60}$ Cfr. Hervada, J., Introducción crítica al Derecho Natural, op. cit., pp. 136 137.

${ }^{61}$ Doral García, J. A., "Concepto filosófico y concepto jurídico de persona”, op. cit., p. 113
} 
distinción de realidades. Rey y hombre, por ejemplo, son concepto diferentes, pero uno y otro se predican de la misma realidad singular: el individuo humano que es rey" ${ }^{\prime 62}$. Persona en sentido ontológico y persona en sentido jurídico son conceptos distintos, pero hacen referencia a la misma realidad, que es el ser humano.

La persona en sentido jurídico no es de origen positivo, sino natural, porque los seres humanos, por naturaleza, son sujetos de derecho ${ }^{63}$. De esa manera, como ya se ha señalado en varias ocasiones, la pertenencia biológica a la especie humana es el dato relevante para el reconocimiento de la condición de persona ${ }^{64}$. En consecuencia, siendo el embrión humano un miembro de la especie humana, no queda duda de que el derecho se encuentra ante una persona, ante un sujeto de derecho, a quien se le debe otorgar la protección correspondiente.

En definitiva, y a modo de recapitulación, el embrión humano debe ser reconocido como persona, como sujeto de derecho. Asimismo, la ley positiva no posee legitimidad para privarle de la personalidad, ni limitar sus derechos naturales. Lo único para lo que está facultada es para limitar su capacidad de obrar.

\section{Conclusiones}

$>$ El fundamento ontológico del derecho radica en el respeto a la persona y a su dignidad. De ello se deriva la necesaria protección del derecho a la vida en todas sus etapas de desarrollo.

$>$ La idea de que todo ser humano es una persona es una conquista, no solo del derecho civil, sino del derecho en general. Este presupuesto se encuentra

\footnotetext{
${ }^{62}$ Cfr. HeRvadA, J., Introducción crítica al Derecho Natural, op. cit., p. 137.

${ }^{63}$ Cfr. Ibidem., p. 140.

${ }^{64}$ Spaemann, R., Personas. Acerca de la distinción entre "algo" y "alguien", op. cit., p. 236.
}

fundamentado en la propia estructura humana, de tal modo que para tener la condición de persona (tanto desde el plano ontológico como jurídico), solo se requiere un criterio: la pertenencia biológica a la especie humana ${ }^{65}$.

$>$ El Derecho no crea una realidad nueva, sino que parte de una realidad concreta, ya dada, que es la persona. Por ello, la función del derecho debe limitarse a reconocer la cualidad de persona a todo ser humano, sin discriminar a ninguno.

Siendo el embrión humano un miembro de la especie humana, no queda duda de que el derecho se encuentra ante una persona, ante un sujeto de derecho, a quien se le debe otorgar la protección correspondiente.

\section{Bibliografía}

Aparisi M. A. (2001). "La dignidad humana como fundamento del orden jurídico positivo" Conferencia inaugural de la Facultad de derecho de la Universidad de Istmo Guatemala.

Aparisi A. (2013, diciembre), "El principio de la dignidad humana como fundamento de un bioderecho global" en Cuadernos de Bioética, Vol. XXIV/2.

Ballesteros, J. (coord.), Aparisi M. Á.,(2002). La humanidad in vitro, Granada: Comares.

Ballesteros, J. (1999). "Individualismo y universalidad de los derechos", en Persona y Derecho.

\footnotetext{
${ }^{65}$ Spaemann, R., Personas. Acerca de la distinción entre "algo" y "alguien", op. cit., p. 236. Como se puso de manifiesto en el segundo capítulo, "(...) aquello que es relevante para el reconocimiento del ser de la persona es su pertenencia, por naturaleza, a la especie humana" (PALAZZANI, L., "El concepto de persona en el debate bioético y biojurídico actual", en Medicina y Ética, 1 , (1997), p. 29).
} 
Barbero, D. (1967). Sistema del derecho privado, vol. I, Buenos Aires: Editorial Jurídicas Europa - América.

Bellver, V. (2002), "Estatuto jurídico del embrión humano", en La humanidad in vitro, Granada.

Díaz M. (2005), Derecho y nueva eugenesia: un estudio desde la ley 35/88, de 22 de noviembre de técnicas de reproducción asistida, Pamplona: EUNSA.

Díez P. L. y Gullón B., A. (1994), Sistema de Derecho Civil, (vol. 1), Madrid: Civitas.

Doral G. J. (1975), "Concepto filosófico y concepto jurídico de persona", en Persona y Derecho.

García A., M. (1979), Instituciones de Derecho civil, (vol. I), Editorial Revista de Derecho Privado.

Hervada, J. (1981). "Concepto jurídico y concepto filosófico de persona", en La Ley, 1.

Hervada, J. (2008). Lecciones propedéuticas de filosofía del derecho, Pamplona: EUNSA.

Hervada, J. (1981), Introducción crítica al Derecho Natural, Pamplona: EUNSA.

Hoyos C. L. (1989). El concepto jurídico de persona, Pamplona: EUNSA.

Martínez A., Aldaz, C. (2001). “¿El nacimiento determina la personalidad? (Reflexiones sobre el concepto jurídico de persona, con un epílogo sobre la situación jurídica del concebido)", en Actualidad Civil, 31.

Martínez P. A. (1992). "Los derechos humanos como derechos inalienables" en Derechos humanos, Madrid: Tecnos.
Montes P. V. (1995), "El significado institucional de la idea de persona", Derecho civil. Parte general, Valencia: Tirant lo Blanch,.

Gabaldón, J. (2001), “Libre desarrollo de la Personalidad y derecho a la vida", en Persona y Derecho, Madrid: Editorial Aranzadi Civitas.

Ollero T. A. (2006), "Todos tiene derecho a la vida ihacia un concepto constitucional de persona?", en Bioderecho entre la vida y la muerte, Navarra: Thomson-Aranzadi, Cizur Menor.

Palazzani, L. (1997), “El concepto de persona en el debate bioético y biojurídico actual", en Medicina y Ética.

Peñaranda, E. (2006), Los Nuevos Desafíos de Reproducción Asistida, Reflexiones Éticas y jurídicas desde la perspectiva del Derecho Penal, Madrid: Editorial Fundación Medicina y Humanidades médicas.

Sánchez B. R. (2008). "Protección de la Vida Prenatal, con especial relevancia en el Derecho Constitucional Español", en Revista de la Universidad Católica Santo Toribio de Mogrovejo, Chiclayo.

Spaemann, R. (2000), Personas. Acerca de la distinción entre "algo" y "alguien", Pamplona: EUNSA.

Ley de donación y utilización de embriones y fetos humanos o de sus células, tejidos $u$ órganos (Ley 42/1988, de 28 de diciembre) en BOE Núm. 314, de 31 de diciembre de 1988, pp. 6766 a 36767. https://www.boe.es/boe/dias/1988/12/31/p dfs/A36766-36767.pdf (visitado: 12 de julio 2016).

Ley sobre Técnicas de Reproducción Asistida (Ley 35/1988, de 22 de noviembre) en BOE 
Núm. 282, de 24 de noviembre de 1988, pp. 33373 a 33378.

https://www.boe.es/boe/dias/1988/11/24/pdfs/A3 3373-33378.pdf (visitado: 12 de julio 2016).

La Constitución Política del Perú
STCE 53/1985, de 11 de abril 1985 STCE 212/1996, de 19 de diciembre de 1996 STCE 116/1999, de 17 de junio de 1999 